\title{
Molecular Typing of Methicillin-Resistant Staphylococcus aureus by Polymerase Chain Reaction: Distribution of the Typed Strains in Hospitals
}

\author{
Shuji Tohda, Miki Maruyama and Nobuo Nara
}

\begin{abstract}
Three methods for molecular typing of methicillin-resistant Staphylococcus aureus using polymerase chain reaction (PCR) were compared. The method which amplified the variable number of tandem repeat of $d r u$ sequences grouped the isolates into six types. Whereas, the method examining restriction fragment length polymorphism of coagulase gene and the method using arbitrarily primed-PCR showed poor diversity in typing. We investigated the distribution of $d r u$ types in two hospitals. Obvious concentration of a type in one ward was not recognized in our hospital. In the other hospital, a rare type was detected from the inpatients in the pediatrics ward. It suggested that the infection was an epidemic. We also found that some patients were infected with more than two strains. Even if two isolates show the same type, it does not necessarily mean that they originated from one clone. However, this method brings meaningful information on nosocomial infection, more easily than other genotyping.

(Internal Medicine 36: 694-699, 1997)
\end{abstract}

Key words: dru sequence, nosocomial infection, coagulase gene

\section{Introduction}

Nosocomial infection caused by methicıllin-resistant Staphylococcus aureus (MRSA) has been a serious problem in hospitals (1). To prevent infection, it is imperative to determine whether the infection is epıdemic, sporadic, or endogenous; if it is epidemic, it is helpful to know how the organisms spread in the hospital. To investigate this, it is necessary to differentiate the strains isolated from patients. Molecular typing of the strains is useful for this purpose.

For genotyping of MRSA, several methods have been reported. Plasmıd analysis was reported by McGowan et al (2). Although this method has strong discriminatory power, about $10 \%$ of strains can not be analyzed as they have no plasmid (3). Ribotypıng (4) is also useful to discriminate isolates. However, this method takes a few days to perform. DNA fingerprinting by pulsed-field gel electrophoresis (PFGE) (5) has been also reported to have strong discriminatory power. Ichiyama et al (5) reported identification of 31 different patterns by PFGE. However, this method requires special equipment and technique and takes several days.

Recently, some types of DNA polymorphism by means of polymerase chain reaction (PCR) have been reported. This method is easier and takes much less time than other methods described above. In the present study, we performed the genotyping of a large number of MRSA strains isolated from patients using three kinds of PCR-based methods; variable number of tandem repeat (VNTR) of $d r u$ sequences $(6,7)$, restriction fragment length polymorphism (RFLP) of coagulase gene $(8,9)$, and arbitrarily primed (AP) - PCR method reported by van Belkum et al (10). We examined the usefulness of the three PCR-base genotyping methods with clinical samples. Furthermore, we investigated the distribution of the typed strains among the wards in hospitals.

\section{Materials and Methods}

\section{MRSA strains and DNA preparation}

All the isolates of MRSA were collected from clinical samples at the clinical microbiology laboratory in our hospital in Tokyo from March to May in 1996. The sources of the samples included sputum, throat swabs, blood, stool, urine, pus, ascites, and catheters. A total of 120 isolates were collected from 75 patients in our hospital. For reference, 39 isolates were also collected from 24 patients in Toride Kyodo Hospital ( $\mathrm{T}$ hosp.), a local general hospital located 50 kilometers north of

From the Department of Laboratory Medicine, Tokyo Medical and Dental Unıversity, Tokyo

Received for publication March 4, 1997, Accepted for publication June 10, 1997

Reprint requests should be addressed to Dr Shujı Tohda, the Department of Laboratory Medıcine, Tokyo Medical and Dental Unıversity, 1-5-45 Yushıma Bunkyo-ku, Tokyo 113 
Tokyo. For DNA preparation, a colony on MRSA screen agar plate containing $6 \mu \mathrm{g} / \mathrm{ml}$ oxacillin and $4 \% \mathrm{NaCl}$ (Becton Dickinson, Lincoln Park, NJ) was picked up, put into $500 \mu \mathrm{l}$ of water in microtube and boiled for 15 minutes. After centrifugation, the supernatant was used as a DNA sample for PCR.

\section{PCR-VNTR of dru element}

The dru element consists of a repeated sequence of 40 base pairs (bp). This element is located near the mecA gene (6). The dru element was amplified by PCR according to the method reported by Nishi et al (7). Briefly, cell lysate $(5 \mu \mathrm{l})$ was added to a PCR mixture containing $1 \mu \mathrm{mol}$ of each primer, $200 \mu \mathrm{mol}$ deoxynucleotide triphosphate, and $0.5 \mathrm{U}$ of $T a q$ polymerase (Takara Shuzo, Kyoto) in a final volume of $100 \mu$ l. The primers were sense 5'ACTATTCCCTCAGGCGTCC3' and antisense 5'GGAGTTAATCTACGTCTCATC3'. After denaturation at $94^{\circ} \mathrm{C}$ for 3 minutes, reactions were performed for 30 cycles consisting of 1 minute at $94^{\circ} \mathrm{C}, 1$ minute at $55^{\circ} \mathrm{C}$, and 2 minutes at $72^{\circ} \mathrm{C}$, followed by final elongation at $72^{\circ} \mathrm{C}$ for 7 minutes in a GeneAmp PCR system 2,400 thermocycler (Perkin-Elmer Cetus, Norwalk, CT). The PCR products were electrophoresed through an agarose gel and stained with ethidium bromide. Band sizes were determined by comparison with 100 bp DNA ladder standards (BRL Life Technology, Bethesda, MD) run concurrently. Each examination was performed in duplicate to ascertain the reproducibility.

\section{PCR-RFLP of coagulase gene}

The 3 ' end region of the coagulase gene was amplified by nested PCR according to the method reported by Goh et al (8) and Yamashita et al (9) with modification. The amplified region contains $81 \mathrm{bp}$ tandem repeat sequences. Cell lysate was added to a PCR mixture as described above, and subjected to 30 PCR cycles, each consisting of 1 minute at $94^{\circ} \mathrm{C}, 2$ minutes at $59^{\circ} \mathrm{C}$, and 3 minutes at $72^{\circ} \mathrm{C}$. For nesting, $2 \mu \mathrm{l}$ of the first PCR product was added to a fresh PCR mixture and subjected to 30 PCR cycles, each consisting of 1 minute at $94^{\circ} \mathrm{C}, 2$ minutes at $56^{\circ} \mathrm{C}$, and 3 minutes at $72^{\circ} \mathrm{C}$. The outer primers were $5^{\prime}$ ATACTCAACCGACGACACCG3' and 5'GATTTTGGATGAAGCGGATT3'. The inner primers were 5'GCAAGACCAAGATTCAACAA3' and 5'AAAGAAAACCACTCACATCA3'. The nested PCR product was digested with the restriction endonuclease Alu I (Takara). Both the nested PCR products and the restriction digest fragments were electrophoresed through an agarose gel and stained with ethidium bromide.

\section{$A P-P C R$}

Cell lysate was added to the PCR mixture described above, and subjected to 40 PCR cycles using both the arbitrary primer and the primer which was originally designed for ERIC2 region, according to the method reported by van Belkum et al (10). The sequences of the primers were 5'TACATTCGAGGACCCCTAAGTG3' and 5'AAGTAAGTGACTGGGGTGAGCG3', respectively. The cycles consisted of 1 minute at $94^{\circ} \mathrm{C}, 1$ minute at $25^{\circ} \mathrm{C}$, and 2 minutes at $74^{\circ} \mathrm{C}$. The PCR products were electrophoresed through an agarose gel and stained with ethidium bromide.

\section{Results}

\section{Preliminary experiments}

First, we examined whether the $d r u$ type of the colonies on a plate is generally uniform or diverse. If it is diverse, it is necessary to pick up many colonies from one plate to investigate. We selected five plates randomly and eight colonies were picked up from each plate. Then, the $d r u$ type of each colony was examined. As a result, eight colonies from each plate showed the identical dru type (data not shown).

Next, we examined the stability of the $d r u$ element. Because, if the $d r u$ type of a strain changes quickly within a short period, the genotyping is meaningless. Briefly, a colony was picked up and cultured in $5 \mathrm{ml}$ of liquid medium. Then, $50 \mu \mathrm{l}$ of the suspension was transferred into $5 \mathrm{ml}$ of fresh medium. This procedure was repeated five times, which meant $10^{10}$ fold amplification, followed by plating on agar. Six colonies from the plate and the original colony were analyzed. The seven samples showed the same genotype (data not shown). This result denied the changeability of the $d r u$ element within a short period.

\section{Typing of VNTR of dru element}

In the 120 MRSA isolates from our hospital, we observed 5 different sizes of PCR products for $d r u$ element: approximately 410, 450, 490, 530, and 570 bp (Fig. 1). In addition, a PCR product of $210 \mathrm{bp}$ was observed from the isolates in Thospital. In this paper, we assigned the strain from which PCR product was $410,450,490,530,570$, and $210 \mathrm{bp}$, types A, B, C, D, E,

\section{$\begin{array}{lllllll}\text { Sample No. } & 102 & 103 & 78 & 101 & 92 & \text { T hosp } 33\end{array}$}

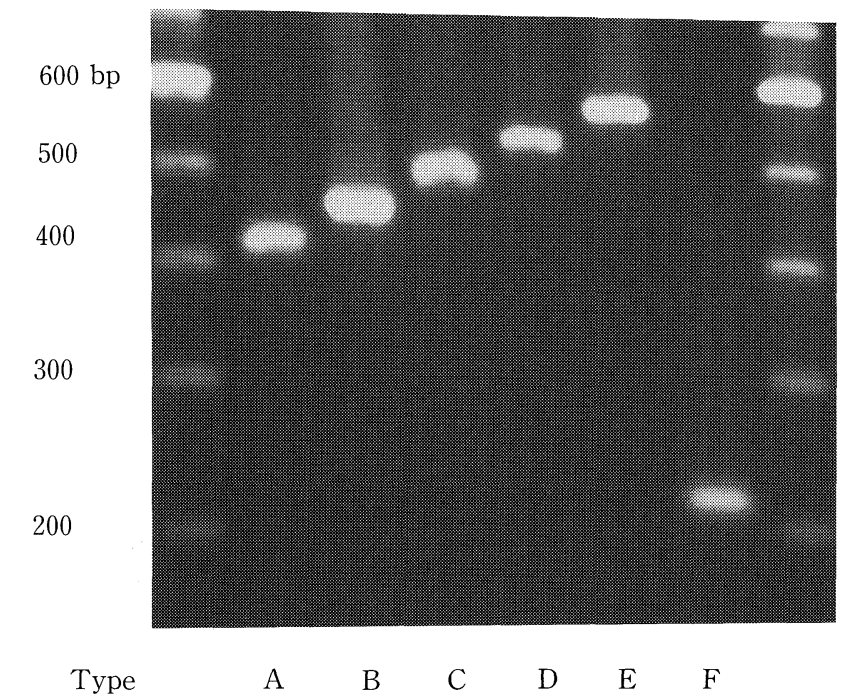

Figure 1. PCR-VNTR of $d r u$ element. PCR products from representative MRSA isolates were electrophoresed. Each type is assigned a letter from $A$ to $F$. Molecular size markers are indicated on both sides. 
and $\mathrm{F}$, respectively.

The distribution of $d r u$ types among wards in our hospitals is shown in Table 1. If an identical type was detected repeatedly from multiple samples from one patient, these were counted as one strain in this table. Accordingly, the total number of strains totaled 90. For reference, the distribution of the types in $T$ hospital and Kagoshima University hospital (K hosp.) located at the south end of Japan is also shown. The data in the latter hospital is cited from the paper reported by Nishi et al (7). As the sizes of the PCR products they reported were slightly different from ours, we adapted our standard to their data in this table.

From twenty-two patients in our hospital, plural samples were sent to the laboratory during this period. From ten patients out of twenty-two, two types of MRSA were detected. In seven patients out of these ten, two types of MRSA were detected from the same site of isolation. Moreover, three patients had three types of MRSA detected. The details are shown in Table 2.

Table 3 shows the relationship between the antibiogram and dru typing. For types B, E, and F, the strains in each type showed the identical antibiogram. The strains in the other types showed diverse antibiogram.

\section{RFLP of coagulase gene}

All the isolates in our hospital showed 810 bp of nested PCR product for coagulase gene (Fig. 2; right side). For all the strains except one, the $A l u$ I restriction fragment length pattern consisted of 81,243 , and $486 \mathrm{bp}$. Several faint bands seen in the lane seemed to be the fragments due to partial digestion. One strain, which was categorized in $d r u$ type E, showed the fragments of 162, 243, 405 bp (Fig. 2; left).

All the isolates in T hospital also showed 810 bp of PCR products. One strain, which was categorized in $d r u$ type E, showed the fragments of 162 and $648 \mathrm{bp}$. All the rest showed the fragments of 81,243 , and 486 bp (data not shown).

\section{AP-PCR}

Five different banding patterns of PCR fragments, assigned types I to V, were obtained by AP-PCR (Fig. 3). All the types had the bands of approximately 600, 410, 360, 160, $120 \mathrm{bp}$. In addition to these five bands, type II had the bands of 180, 100, and 80 bp and type III had the bands of 490, 300, 250, and 220 bp. In type IV, the band of $490 \mathrm{bp}$ was visible and the band of $410 \mathrm{bp}$ was faint compared with other bands in the lane. In type $\mathrm{V}$, the bands of 600 and $160 \mathrm{bp}$ were faint or invisible. However, as we considered that types IV and V were essentially identical

Table 1. Distribution of MRSA Types among Wards

\begin{tabular}{|c|c|c|c|c|c|c|c|c|}
\hline \multirow[t]{2}{*}{ Bldg. } & \multirow[t]{2}{*}{ Floor } & \multirow[t]{2}{*}{ Department } & \multicolumn{6}{|c|}{ No. of isolates of type } \\
\hline & & & A & $\mathrm{B}$ & $\mathrm{C}$ & $\mathrm{D}$ & $\mathrm{E}$ & $\mathrm{F}$ \\
\hline A & 6 & ICU & 0 & 0 & 0 & 1 & 0 & 0 \\
\hline A & 8 & Pediatrics & 2 & 0 & 0 & 1 & 0 & 0 \\
\hline $\mathrm{A}$ & 9 & Intern. Surg. & 4 & 2 & 1 & 5 & 0 & 0 \\
\hline A & 10 & Neurosurgery & 3 & 0 & 0 & 2 & 0 & 0 \\
\hline A & 11 & Orthopedics & 0 & 0 & 0 & 1 & 0 & 0 \\
\hline A & 12 & Surgery & 2 & 0 & 1 & 5 & 0 & 0 \\
\hline A & 13 & Radiology & 2 & 0 & 0 & 1 & 0 & 0 \\
\hline A & 15 & Internal & 3 & 1 & 0 & 6 & 0 & 0 \\
\hline A & & subtotal & 16 & 3 & 2 & 22 & 0 & 0 \\
\hline $\mathrm{B}$ & 2 & Surgery & 0 & 0 & 0 & 1 & 0 & 0 \\
\hline B & 5 & Gynecology & 2 & 0 & 0 & 1 & 0 & 0 \\
\hline $\mathrm{B}$ & 6 & Urology & 3 & 0 & 1 & 1 & 0 & 0 \\
\hline B & 7 & Dermatol. ENT. & 9 & 1 & 0 & 6 & 1 & 0 \\
\hline B & 8 & Respiratory & 3 & 2 & 0 & 1 & 0 & 0 \\
\hline $\mathrm{B}$ & & subtotal & 17 & 3 & 1 & 10 & 1 & 0 \\
\hline \multicolumn{3}{|c|}{ Outpatient clinic } & 4 & 0 & 1 & 10 & 0 & 0 \\
\hline \multicolumn{3}{|l|}{ Total } & 37 & 6 & 4 & 42 & 1 & 0 \\
\hline \multicolumn{3}{|c|}{ T hosp. } & 0 & 0 & 0 & 21 & 1 & 3 \\
\hline \multicolumn{3}{|c|}{ *K hosp. } & 56 & 1 & 26 & 0 & 22 & $0^{* *}$ \\
\hline
\end{tabular}

The types were determined by PCR-VNTR of $d r u$ element. *The data in K hosp. are cited from the paper reported by Nishi et al (7) with modification for reference. **Another type showing $250 \mathrm{bp}$ of PCR product was reported in their paper. 
to type I, we grouped the strains into three types. Consequently, 84,2 , and 2 isolates were grouped into types I, II and III, respectively. As the remaining 32 isolates showed an obscure banding pattern, typing was impossible. No clear relationship was recognized between typing of $\mathrm{A}$ to $\mathrm{E}$ and typing of I, II and III.

For the isolates in $\mathrm{T}$ hospital, 31 isolates showed type I pattern. The remaining eight isolates could not be grouped as their banding patterns were obscure.

\section{Discussion}

Here, we examined the usefulness of the three PCR-based

Table 2. List of the Patients Infected with Three Types of MRSA

\begin{tabular}{|c|c|c|c|c|}
\hline Patient & Ward & Date & Source & Type \\
\hline \multirow[t]{8}{*}{ N.M. } & A 9 & Mar. 26 & sputum & $\mathrm{D}$ \\
\hline & & Apr. 1 & ascites & $\mathrm{D}$ \\
\hline & & Apr. 1 & stool & $\mathrm{D}$ \\
\hline & & Apr. 8 & pus & $\mathrm{A}$ \\
\hline & & Apr. 9 & stool & $\mathrm{C}$ \\
\hline & & May 8 & stool & $\mathrm{D}$ \\
\hline & & May 9 & pus & $\mathrm{D}$ \\
\hline & & May 10 & throat & $\mathrm{D}$ \\
\hline \multirow[t]{4}{*}{ M.N. } & B 8 & Mar. 18 & sputum & A \\
\hline & & Apr. 10 & sputum & $\mathrm{B}$ \\
\hline & & Apr. 15 & decubitus & $\mathrm{D}$ \\
\hline & & May 9 & decubitus & A \\
\hline \multirow[t]{3}{*}{ M.S. } & A 15 & Apr. 11 & throat & A \\
\hline & & Apr. 15 & stool & $\mathrm{D}$ \\
\hline & & Apr. 22 & throat & B \\
\hline
\end{tabular}

The types were determined by PCR-VNTR of $d r u$ element. genotyping methods with a large number of clinical materials. As shown above, the method of VNTR of $d r u$ element grouped the MRSA isolates into six different types. This method is easy to perform, takes only a few hours to complete and is clearly interpretable as it gives only one band. Moreover, as the target region is linked to mec A gene (6), the detection of this PCR product can verify that this isolate is methicillin-resistant. In

Table 3. Relationship between Antibiogram and dru Typing

\begin{tabular}{|c|c|c|c|c|c|c|c|c|c|c|}
\hline \multirow[b]{3}{*}{ IPM } & \multirow{3}{*}{$\begin{array}{l}\text { Antibiogran } \\
\text { MINO }\end{array}$} & \multirow[b]{3}{*}{ OFLX } & \multicolumn{8}{|c|}{ No. of isolates of type } \\
\hline & & & \multicolumn{5}{|c|}{ Our Hospital } & \multicolumn{3}{|c|}{ T Hospital } \\
\hline & & & $\mathrm{A}$ & $\mathrm{B}$ & $\mathrm{C}$ & $\mathrm{D}$ & $\mathrm{E}$ & $\mathrm{D}$ & $\mathrm{E}$ & $\mathrm{F}$ \\
\hline $\mathrm{R}$ & $\mathrm{S}$ & $\mathrm{R}$ & 17 & 0 & 2 & 19 & 0 & 2 & 0 & 0 \\
\hline $\mathrm{R}$ & I & $\mathrm{R}$ & 17 & 6 & 1 & 23 & 0 & 0 & 0 & 3 \\
\hline $\mathrm{R}$ & $\mathrm{R}$ & $\mathrm{R}$ & 0 & 0 & 0 & 0 & 0 & 19 & 0 & 0 \\
\hline $\mathrm{R}$ & $\mathrm{I}$ & I & 2 & 0 & 1 & 0 & 0 & 0 & 0 & 0 \\
\hline I & $\mathrm{S}$ & $\mathrm{R}$ & 1 & 0 & 0 & 0 & 0 & 0 & 0 & 0 \\
\hline $\mathrm{S}$ & $\mathrm{S}$ & $\mathrm{S}$ & 0 & 0 & 0 & 0 & 1 & 0 & 1 & 0 \\
\hline
\end{tabular}

IPM: imipenem, MINO: minocycline, OFLX: ofloxacin, R: resistant, I: intermediate, S: susceptible. 


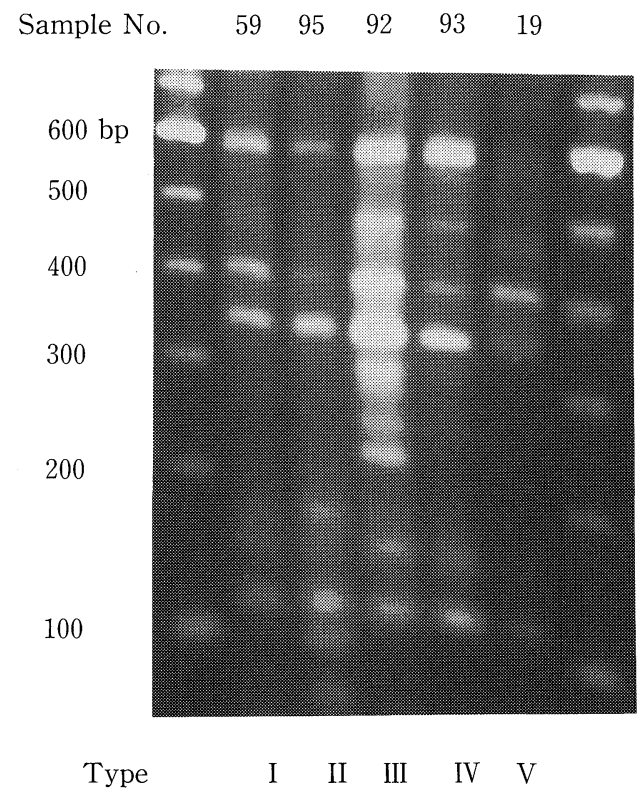

Figure 3. AP-PCR products from representative MRSA isolates are shown. Each banding pattern is assigned a number from I to $V$. Molecular size markers are indicated on both sides.

this study, the diversity of $d r u$ types was slight. However, the strain showing $250 \mathrm{bp}$ of PCR product was reported by Nishi et al (7) and the strains showing $331 \mathrm{bp}$ and $611 \mathrm{bp}$ of PCR products were reported by Kagawa et al (11). Accordingly, a total of 9 different types have been observed until now. Based on the nucleotide sequence of this region $(6,7)$, the size of the PCR product is expected to be $40 \times \mathrm{N}+171 \mathrm{bp}$. N indicates the number of repeats. Therefore, some more types which show a different size of the PCR product should exist, and thus, the discriminatory power of this method is not so poor.

Regarding RFLP of coagulase gene, Goh et al (8) reported observation of 10 RFLP patterns. However, almost all the strains in our hospital and T hospital showed the same pattern. Goh et al (8) examined both MRSA and methicillin-sensitive SA and the strains were collected from many hospitals. This may be the reason why their investigation showed such diversity. At any rate, our results show that even if many MRSA isolates show the same RFLP pattern of coagulase gene, it does not mean they originate from a single clone.

As for AP-PCR method, although we observed five banding patterns, most of the isolates showed the type I pattern. For several isolates, some of the bands were so faint that it was impossible to decide the type, as was often the case with the APPCR method. Accordingly, this method was not useful for us. van Belkum et al (12) undertook a multicenter evaluation of AP-PCR for genotyping of MRSA. They reported that their method could discriminate 16 to 30 different types. However, they also mentioned that this method had problems in interlaboratory reproducibility and interpretation of DNA fingerprints.
In the present study, we also investigated the distribution of the $d r u$ types among the wards in our hospital. As shown in Table 1, type A and type D strains were predominant in our hospital. Type A strains were predominant in building A and type $\mathrm{D}$ strains were predominated in building $\mathrm{B}$, although these were not significant differences. The obvious concentration of a single type in one ward was not recognized in our hospital.

In Thospital, MRSA was detected from three inpatients who had become feverish successively in the pediatrics ward. We found that these patients had type F MRSA. This type was not detected in the other wards and it was a rare type according to our investigation. These findings supported the supposition that the episode was not sporadic or endogenous, but epidemic in the ward.

Regarding the cause of the predominance of type A and type D strains in our hospital, two hypotheses are considered. The first is that type A and type D strains have gradually prevailed by nosocomial infection in our hospital. The second is that type $\mathrm{A}$ and type $\mathrm{D}$ strains are universally predominant. To examine the second hypothesis, we compared the distribution in our hospital and in T hospital and $\mathrm{K}$ hospital. We found that the predominant types were different among the three. Accordingly, the second hypothesis seems less possible. To solve this problem, continuous investigation at numerous hospitals is needed.

In this study, we found that some patients were infected with more than two kinds of strains. As for the cause, the following interpretations are considered: 1) A patient may have various MRSA at one focus. 2) Different kinds of MRSA may exist at different foci or organs. 3) Some strains may be replacing sequentially. 4) The length of the $d r u$ element itself may change although an identical strain stays on. The first interpretation seems less possible because more than two types of strains were not detected from one agar plate according to the sampling examination (data not shown). We denied the fourth hypothesis in the section of Preliminary experiments in Results. To conclude these four interpretations, much further investigation is required.

The analysis of the relationship between antibiogram and genotyping was difficult because the diversity of antibiogram for MRSA was poor. Clear correspondence between the two was not recognized. Interestingly, type E strains isolated in our hospital and in $\mathrm{T}$ hospital showed identical and distinctive antibiograms. The fact that the isolates in type A showed four different antibiograms may suggest that the isolates in type A consisted of at least four clones. By combining the genotyping and antibiogram, we may be able to make the discriminatory power stronger.

We conclude that PCR-VNTR of $d r u$ element is the best discriminatory method of the three methods examined. It should be performed as the first step in the hospitals in which other molecular typing such as PFGE can not be performed. Even if two isolates show the same $d r u$ type, it does not necessarily mean that they originated from one clone. However, this method brings meaningful information for nosocomial infection, more easily than other genotyping. 


\section{Genotyping of MRSA by PCR}

Acknowledgements: We thank Dr. K. Hattori and Mr. F. Kasahara (Toride Kyodo hospital) for providing samples. We also thank the staff of the clinical laboratory in our hospital for their cooperation. This work was supported in part by Yokoyama Clinical Pharmacology Research Foundation, Nagoya, Japan and the Clinical Pathology Research Foundation of Japan.

\section{References}

1) Brumfitt W, Hamilton-Miller J. Methicillin-resistant Staphylococcus aureus. N Engl J Med 320: 1188, 1989.

2) McGowan JE Jr, Terry PM, Huang TS, Houk CL, Davies J. Nosocomial infections with gentamicin-resistant Staphylococcus aureus: plasmid analysis as an epidemiologic tool. J Infect Dis 140: 864, 1979.

3) Hartstein AI, Phelps CL, Kwok RY, Mulligan ME. In vivo stability and discriminatory power of methicillin-resistant Staphylococcus aureus typing by restriction endonuclease analysis of plasmid DNA compared with those of other molecular methods. J Clin Microbiol 33: 2022, 1995.

4) Blumberg HM, Rimland D, Kiehlbauch JA, Terry PM, Wachsmuth IK. Epidemiologic typing of Staphylococcus aureus by DNA restriction fragment length polymorphisms of rRNA genes: Elucidation of the clonal nature of a group of bacteriophage-nontypeable, ciprofloxacin-resistant, methicillin-susceptible S. aureus isolates. J Clin Microbiol 30: 362, 1992.

5) Ichiyama S, Ohta M, Shimokata K, Kato N, Takeuchi J. Genomic DNA fingerprinting by pulsed-field gel electrophoresis as an epidemiological marker for study of nosocomial infections caused by methicillin-resistant Staphylococcus aureus. J Clin Microbiol 29: 2690, 1991.
6) Ryffel C, Bucher R, Kayser FH, Berger-Bachi B. The Staphylococcus aureus mec determinant comprises an unusual cluster of direct repeats and codes for a gene product similar to the Escherichia coli snglycerophosphoryl diester phosphodiesterase. J Bacteriol 173: 7416, 1991.

7) Nishi J, Miyanohara $H$, Nakajima $T$, et al. Molecular typing of the methicillin resistant determinant ( $\mathrm{mec}$ ) of clinical strains of Staphylococcus based on mec hypervariable region length polymorphisms. Rinsho Byori (Jpn J Clin Pathol) 42: 1227, 1994 (Abstract in English).

8) Goh SH, Byrne SK, Zhang JL, Chow AW. Molecular typing of Staphylococcus aureus on the basis of coagulase gene polymorphisms. J Clin Microbiol 30: 1642, 1992.

9) Yamashita K, Yamanaka S, Kagawa S, Matsuoka A. DNA polymorphisms in strains of Staphylococcus aureus. Usefulness of coagulase gene as an epidemiological marker. Rinsho Byori (Jpn J Clin Pathol) 43: 61, 1995 (Abstract in English).

10) van Belkum A, Bax R, Peerbooms P, Goessens WH, van Leeuwen N, Quint WG. Comparison of phage typing and DNA fingerprinting by polymerase chain reaction for discrimination of methicillin-resistant Staphylococcus aureus strains. J Clin Microbiol 31: 798, 1993.

11) Kagawa S, Yamashita K, Matsuoka A. Genotyping of methicillin-resistant Staphylococcus aureus (Abstract). Rinsho Byori (Jpn J Clin Pathol) 44 (suppl.): 117, 1996.

12) van Belkum A, Kluytmans J, van Leeuwen W, et al. Multicenter evaluation of arbitrarily primed PCR for typing of Staphylococcus aureus strains. J Clin Microbiol 33: 1537, 1995. 